\title{
Influence of geological factors on coal permeability in the Sihe coal mine
}

\author{
Guangui Zou ${ }^{1,2} \odot \cdot$ Qianhua Zhang ${ }^{2} \cdot$ Suping Peng ${ }^{1} \cdot$ Jiasheng She ${ }^{2} \cdot$ Deliang Teng $^{2} \cdot$ Chaochao Jin $^{2} \cdot$ Yuyan Che $^{2}$
}

Received: 11 January 2021 / Accepted: 17 January 2022

(c) The Author(s) 2022

\begin{abstract}
Permeability of coal reservoirs influence the extraction of coal gas from coal seams. Twelve coal samples were collected at an anticline and a syncline of the No. 3 coal seam in the Sihe coal mine. Porosity, permeability, pore size, vitrinite reflectance, and liquid nitrogen adsorption of the samples were evaluated. Structural curvatures at the sample locations, and the distance between the sampling locations and the nearest faults were calculated based on seismic data. The influences of the evaluated parameters on permeability were analyzed. Major factors that influence permeability of the No. 3 coal seam were extracted using principal component analysis (PCA). Based on the porosity-permeability model derived from the Archie formula and classic Kozeny-Carman equation, we deduced that the permeability of coal increased with an increase in porosity. With an increase in average vitrinite reflectance, permeability decreases first and then increases. PCA results showed that coal permeability was regulated by three key components representing three modes. The first component included pore size, depth, and pore complexity accounting for $52.59 \%$ of the variability indicating that it was the most important in controlling permeability. The second component included specific surface area, structural curvature, and porosity, and the third component comprised of specific surface area, porosity, and average vitrinite reflectance. Overall, pore diameter and complexity had significant effects on coal permeability. The results show that researchers and stakeholders must consider the interactions among multiple factors rather than single factors to understand the influences on permeability to facilitate efficient utilization of coalbed methane resources.
\end{abstract}

Keywords Coal mine $\cdot$ Permeability $\cdot$ Geological factors $\cdot$ Principal component analysis

\section{Introduction}

Permeability of coal reservoirs reflect the flow performance of fluids such as coal gas in coal seams and it is important for the simulation and identification of fluid systems in coal seams (Harpalani and Schraufnagel 1990).

It is important to understand the factors that influence coal permeability for the successful exploration of coalbed methane. Therefore, many studies have been conducted on factors that control coal permeability such as fissures, coal rank, fracture aperture, geological structures, and stress on strata (Shen et al. 2010; Shi et al. 2018a, b; Zhang et al.

Guangui Zou

zgg@cumtb.edu.cn

1 State Key Laboratory of Coal Resources and Safe Mining, Beijing, China

2 College of Geoscience and Surveying Engineering, China University of Mining \& Technology, Beijing, China
2019). Cracks are the main channels for the transport of gas, brine, and other fluids in coal. Cracks in coal are classified as exogenous and endogenous (Gamson et al. 1993; Yao and Liu 2009). Endogenous cracks occur due to the shrinkage in coal volume and internal tensions in coal caused by the influence of temperature and pressure during coal formation. Exogenous cracks are formed by tectonic structures such as faults and folds (Yao et al. 2014). In a previous study, micron-level cracks were studied using micro-CT scanning and fractal theory, and the results showed that micro-crack networks in coals of low ranks have good connectivity and as the rank of coal increases its micro-crack structure becomes more complex (Shi et al. 2018b). As an organic-rich dual-porosity medium, the permeability of coal undergoes a unique evolution because of adsorption/desorption. Unlike elastic strain, sorption-induced strain displays a non-linear behavior with continuously sorbing gas injections, and both types of strains are competing processes in causing the volumetric change in coal (Fan and Liu 2018). 
Coal's permeability is related to effective stress and the mechanism of stress loading and unloading. The average permeability damage of a coal specimen is more sensitive to the maximum loading stress and the loading-unloading path compared to gas-injection pore pressure and holding period. Gas-adsorption induced swelling significantly reduces initial permeability and average permeability damage during cyclic loading (Fan and Liu 2019).

Geological structures have major influences on the permeability of coal. The permeability of coal near a fracture zone of a tensile structure is larger than that in a fracture zone where stress is concentrated (e.g., the high-pressure area squeezed between tectonic movement and thrust nappe structure). The permeability gradients of coal reservoirs in the Shanxi Formation are controlled by the principal stress exerted by the tectonic stress field (Qin et al. 1999). Shi et al. (2018a) conducted coal permeability measurements under constant confining pressure and effective stress and showed that it evolves due to expansion and contraction that are induced by adsorption, instantaneous effective stress, and matrix-fracture interactions. The relationship between coal permeability and pressure sensitivity was studied using coal samples collected from the Xinyuan coal mine in Yangquan city. The study showed the following: (1) permeability of coal exhibits anisotropy, (2) permeability along the strike of the coal seam is higher than that along the direction of propensity (Wang et al. 2018). These observations indicate that coal permeability is highly sensitive to stress anisotropy. Shen et al. (2010) used structural curvature to describe the undulating form of coal seams and analyzed its influence on permeability. They also calculated structural curvature based on contours of the floor of the No. 3 coal seam of the Shanxi Formation in the Qinshui Basin and showed that it is negatively correlated with coal reservoir pressure and positively correlated with coal permeability. These studies analyzed the effect of geological factors on permeability and provided guidance for further analysis.

Observation data containing multiple variables are required to understand the effects of geological influencing factors on coal permeability. Large multivariate data sets can provide a wealth of information for this study. More importantly, in many cases, there may be correlations among various geological factors, thereby increasing the complexity of the analysis. The complex sets of information in the multivariate data sets cannot be fully utilized by analyzing each geological factor separately. Therefore, the reduction of factors without reasoning will lead to the loss of useful information, resulting in erroneous conclusions. Principal component analysis (PCA) is an algorithm for dimensionality reduction, which eliminates redundant indicators, and at the same time, minimizes the loss of information. The principal components are orthogonal to each other. Therefore, each principal component can represent a geological control mode. Our study aims to analyze the relationships between geological factors and coal permeability in the Sihe coal mine. We tested the permeability of coal in the Sihe coal mine. Other parameters such as porosity, structural curvature, and vitrinite reflectance of the coal samples obtained from the Sihe coal mine were also measured. Subsequently, the relationships between the coal parameters on the permeability of coal were analyzed. PCA was employed to understand the factors controlling the permeability of coal.

\section{Coal sample preparation of Sihe coal mine}

In this study, anthracite coal samples were collected from the Sihe coal mine, which is located on the No. 3 coal seam of the Lower Permian Shanxi Formation in Jincheng city, Shanxi Province.

Figure 1 displays the contour map of the No. 3 coal seam in the west mining area based on seismic data. The No. 3 coal seam has folds in the axial direction of NNE. The anticline is located in the western part of the zone with an NNEtrending axis, the two limbs are basically asymmetrical, the inclination of the western limb is $6^{\circ}-10^{\circ}$, the inclination of the eastern limb is slightly greater at $7^{\circ}-14^{\circ}$. The syncline is located in the eastern part of the zone; the axis trends close to NE, the inclination of the two limbs is $6^{\circ}-9^{\circ}$. There are nineteen faults in the fold. A total of 12 coal samples were taken from the No. 3 coal seam. The samples were protected with plastic wrap to ensure that they are not exposed to the air and to prevent damage during transportation. The distance between the sampling point and the nearest fault can be calculated from the map.

\section{Principal component analysis}

The goal of PCA is to recombine initial variables with a certain correlation into a new set of unrelated comprehensive variables (principal components) to replace the original variables. Studying a certain problem involves many variables; if there is a correlation between these variables, then there must be one or more common factors that dominate the data. Based on variable covariance or correlation matrices, original variables are combined to form comprehensive variables (principal components) (Makinde and Lee 2019). These comprehensive variables play a critical role in simplifying the problem while preserving the main information of the original variables, thereby making it easier to understand the main contradictions when studying complex problems (Lam et al. 2020; Mao et al. 2018). 


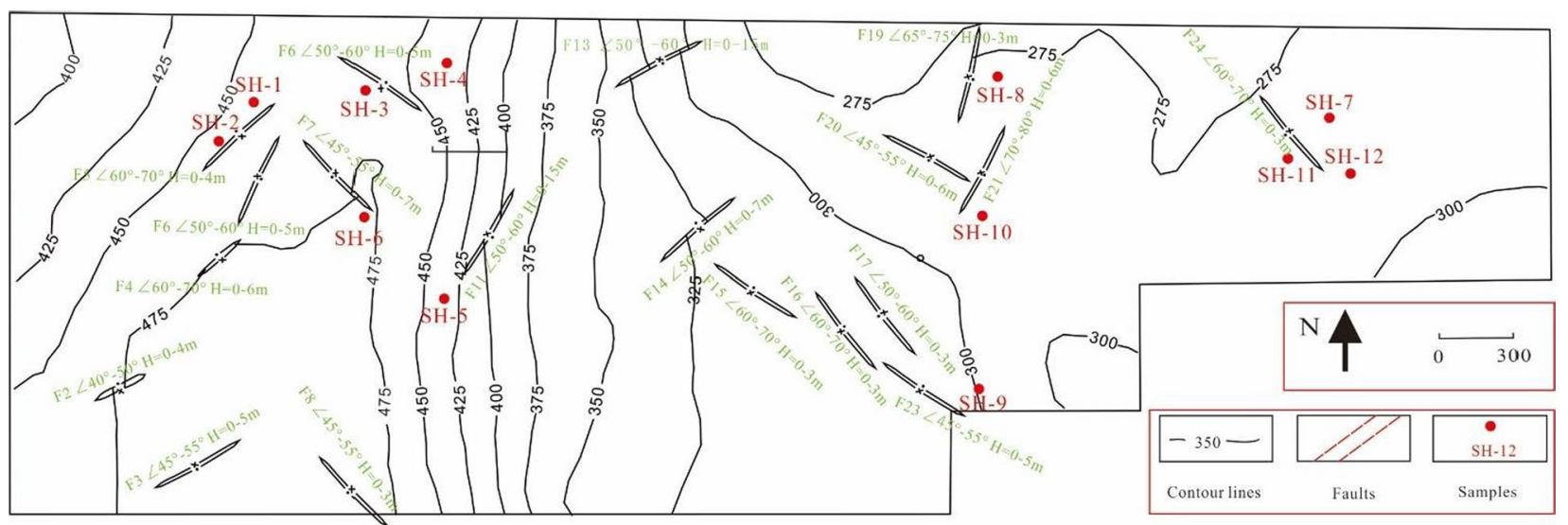

Fig. 1 Contour map of the floor of the No. 3 coal seam and distribution of sampling positions

\subsection{Theory of principal component analysis}

Assume that there are $n$ random variables $X_{1}, X_{2}, \ldots, X_{\eta}$; the $n$-dimensional random vector is $X=\left(X_{1}, X_{2}, \ldots, X_{p}\right)^{\prime}$; the mean value of the random vector $X$ is $\mu$; and the covariance matrix is $\sum$. PCA is used to express these $n$ random variables as $n$ new comprehensive random variables $\boldsymbol{F}_{1}$, $\boldsymbol{F}_{2}, \ldots, \boldsymbol{F}_{n}$ through linear transformation as follows:

$\left\{\begin{array}{c}F_{1}=a_{11} X_{1}+a_{12} X_{2}+\cdots+a_{1 n} X_{1 n} \\ F_{2}=a_{21} X_{1}+a_{22} X_{2}+\cdots+a_{2 n} X_{2 n} \\ \quad \cdots \\ F_{n}=a_{n 1} X_{1}+a_{n 2} X_{2}+\cdots+a_{n n} X_{n n}\end{array}\right.$

Equation (1) can be expressed in the matrix form as follows:

$F=A X$,

where $\boldsymbol{F}=\left(F_{1}, F_{2}, \ldots, F_{n}\right)^{\prime}$ and $\boldsymbol{A}=\left(\begin{array}{ccc}a_{11} & \ldots & a_{1 n} \\ \vdots & \ddots & \vdots \\ a_{n 1} & \cdots & a_{n n}\end{array}\right)=\left(\begin{array}{c}\boldsymbol{a}_{1}^{\prime} \\ \boldsymbol{a}_{2}^{\prime} \\ \cdots \\ \boldsymbol{a}_{n}^{\prime}\end{array}\right)$

Since the linear transformation of Eq. (1) can be arbitrarily performed on the original variables, comprehensive variables $F_{1}, F_{2}, \ldots, F_{n}$ that are obtained through different linear transformations are also different. Therefore, for better linear transformation, $F_{i}(i=1,2, \ldots, n)$ should be mutually independent, and the variance of $F_{i}(i=1,2, \ldots$, $n)$ should be as large as possible. $D\left(F_{i}\right)$ represents the variance of $F_{i}$ and is expressed as follows:

$D\left(F_{i}\right)=D\left(\boldsymbol{a}_{i}^{\prime} \boldsymbol{X}\right)=\boldsymbol{a}_{i}^{\prime} \sum \boldsymbol{a}_{i}$.

However, it is not enough to limit the maximum variance, because for any constant $c$, there is
$D\left(c \boldsymbol{a}_{i}^{\prime} \boldsymbol{X}\right)=c^{2} \boldsymbol{a}_{i}^{\prime} \sum \boldsymbol{a}_{i}$.

Therefore, if there is no restriction on $a$, and $D\left(F_{i}\right)$ is changed arbitrarily, the problem cannot be clarified. Therefore, linear transformation is constrained by the following principles:

(1) $\boldsymbol{a}_{i}^{\prime} \boldsymbol{a}_{i}=1$, i.e., $a_{i 1}^{2}+a_{i 2}^{2}+\cdots+a_{i n}^{2}=1(i=1,2, \ldots, n)$;

(2) $F_{i}$ is not related to $F_{j}$, i.e., $\operatorname{Cov}\left(F_{i}, F_{j}\right)=0(i, j=1,2, \ldots, n ; i \neq j)$;

(3) $F_{1}$ is the largest variance among the linear combinations of $X_{1}, X_{2}, \ldots, X_{n}$ that satisfy Eq. (1); $F_{2}$ is the largest variance of all linear combinations of $X_{1}, X_{2}, \ldots, X_{n}$ that are not related to $F_{1} ; F_{n}$ is has the largest variance among all linear combinations of $X_{1}, X_{2}, \ldots, X_{n}$ that are not related to $F_{1}, F_{2}, \ldots, F_{n-1}$.

Based on these three principles, the integrated variables $F_{1}, F_{2}, \ldots, F_{n}$ are the first, second, $\ldots$, and $n$-th principal components of the original variable, respectively. Equation (3) sequentially decreases the proportion of each principal component in the total variance. In practical problems, the principal components with the largest variances can be selected to replace the original variables. These new comprehensive variables are composed of multiple old variables; thus, they represent the controlling effect of the variables (Du and Du 2018; Ha et al. 2017).

\subsection{Geometric meaning of principal component analysis}

From an algebraic point of view, PCA is a special linear combination of $n$ random variables $X_{1}, X_{2}, \ldots, X_{n}$. From a geometric point of view, these linear combinations are 
obtained by rotating the coordinate system of the original variables $X_{1}, X_{2}, \ldots, X_{n}$ by a certain angle to obtain a new coordinate system. In the new coordinate axis, the maximum possible original variable information (with the largest variance) is included. For example (to illustrate the principle), there are $n$ samples, and each sample has two observed random variables $\left(X_{1}\right.$ and $\left.X_{2}\right)$. The distribution of $n$ samples is in the ellipse form as shown in Fig. 2.

Figure 2 shows that $n$ samples have greater dispersion along the $X_{1}$ or $X_{2}$ axis direction, and the degree of dispersion can be quantitatively determined by the variance of variables $X_{1}$ and $X_{2}$. If only one of the two variables is considered, then the information in the original data will have a greater loss, which implies that $X_{1}$ and $X_{2}$ jointly express the information in the original data. Both are essential when analyzing problems with $X_{1}$ and $X_{2}$. However, through a certain linear combination, the original data can be characterized by new variables $F_{1}$ and $F_{2}$. In geometrical terms, the coordinate axis is rotated counterclockwise by an angle of $\theta$ to obtain new coordinate axes $F_{1}$ and $F_{2}$. The coordinate rotation formula is as follows:

$\left\{\begin{array}{c}F_{1}=X_{1} \cos \theta+X_{2} \sin \theta \\ F_{2}=-X_{1} \sin \theta+X_{2} \cos \theta\end{array}\right.$

The matrix form is expressed as follows:

$\left(\begin{array}{l}F_{1} \\ F_{2}\end{array}\right)=\left(\begin{array}{cc}\cos \theta & \sin \theta \\ -\sin \theta & \cos \theta\end{array}\right)\left(\begin{array}{l}X_{1} \\ X_{2}\end{array}\right)=\boldsymbol{A} \boldsymbol{X}$

where $\mathrm{A}$ is the rotation transformation matrix; $\mathrm{A}$ is an orthogonal matrix, i.e., $\boldsymbol{A}^{\prime}=\boldsymbol{A}^{-1}$.

A new coordinate system was obtained after rotation, as shown in Fig. 2. The $n$ samples have more dispersion in the direction of the $F_{1}$ axis indicating that variable $F_{1}$ contains more information. If variable $F_{2}$ is not considered, there will be no loss of the original variable information. Therefore, after the rotation transformation, the information in the original variables can be concentrated on the $F_{1}$ axis, which condenses

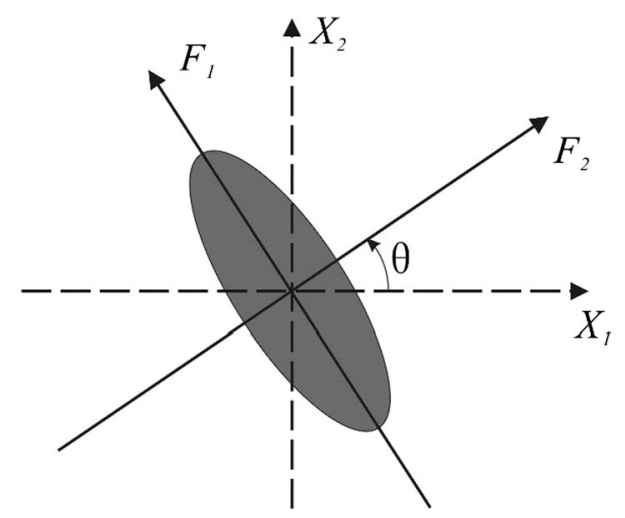

Fig. 2 Geometric interpretation of principal component analysis the information in the data and facilitates analysis. From a geometric point of view, PCA is the rotation process of the coordinate system. The direction of the coordinate axis of each principal component is the direction with the largest degree of dispersion, capturing most of the original variable information (Tran et al. 2019).

\section{Analysis of the influence of geological factors on permeability}

Tests for porosity, permeability, isothermal adsorption, fracture aperture, and vitrinite reflectance were performed on 12 coal samples collected from the No. 3 coal seam in the Sihe mining area. The test results are presented in Table 1. Porosity was measured using a Coberly-Stevens porosimeter. Permeability was measured by the transient method using nitrogen. Standard nitrogen gas adsorption-desorption measurements using liquid nitrogen at a temperature of $77.4 \mathrm{~K}$ were performed on the coal samples. Surface area of each adsorbent was determined using the Brunauer-Emmett-Teller (BET) plot of nitrogen adsorption data. The Frenkel-Halsey-Hill (FHH) model usually uses low-temperature liquid nitrogen adsorption data to obtain the pore fractal dimension of coal. Vitrinite reflectance of these samples was measured using a DM4500P polarizing microscope photometer. Structural curvature was calculated from the contours of the floor of the No. 3 coal seam. Based on these results, the controlling effects of porosity, structural curvature, vitrinite reflectance, and pore structure of coal on permeability were studied. Using the results of the PCA, the mode of control of geological factors on coal permeability was elucidated.

\subsection{Relationship between porosity and permeability}

To study the effect of porosity on permeability, the Kozeny-Carman (KC) equation was used as a porosity-permeability model. The KC equation has been widely used for studying porous media such as sand, mudstone, soil, and oil and gas reservoirs, and is expressed as follows:

$k=C_{\mathrm{kc}} \frac{\phi^{3}}{(1-\phi)^{2}}=\frac{c}{\left(8 a_{v}^{2} \tau\right)} \frac{\phi^{3}}{(1-\phi)^{2}}$

where, $k$ is the permeability; $\phi$ is the porosity; $c$ is introduced as an empirical geometric parameter; $a_{v}$ is the ratio of exposed surface to solid volume; and $\tau$ is the tortuosity, which is defined as the square of the ratio of the effective channel length $L e$ to the length $L$ of the porous body $\left(\tau=(L e / L)^{2}\right)$. Because it is not easy to directly measure tortuosity $\tau=(L e / L)^{2}$, it is common to use the conductivity measured for the same rock saturated with an electrolyte 
Table 1 Test results of coal samples

\begin{tabular}{lllllrlllll}
\hline No. & $P 1$ & $P 2$ & $P 3$ & $P 4$ & \multicolumn{1}{l}{$P 5$} & $P 6$ & $P 7$ & $P 8$ & $P 9$ & $P 10$ \\
\hline SH-1 & 0.0056 & 11.804 & 0.007 & 3.14 & 66.67 & 0.489 & 3.72 & 7.84 & 321 & 2.39 \\
SH-2 & 0.1689 & 13.066 & 0.009 & 3.1 & 22.22 & 0.475 & 4.735 & 12.45 & 315 & 2.51 \\
SH-3 & 0.0143 & 14.758 & 0.010 & 2.88 & 48.89 & 0.685 & 2.986 & 6.17 & 289 & 2.14 \\
SH-4 & 0.0016 & 12.1 & 0.044 & 2.74 & 191.11 & 0.158 & 2.991 & 6.62 & 279.5 & 2.23 \\
SH-5 & 0.0064 & 16.11 & 0.025 & 2.66 & 115.56 & 0.168 & 4.209 & 6.81 & 276 & 2.27 \\
SH-6 & 0.1433 & 15.836 & 0.013 & 3.32 & 35.56 & 0.06 & 4.533 & 12.6 & 331 & 2.49 \\
SH-7 & 0.0008 & 10.086 & -0.014 & 2.934 & 151.11 & 0.081 & 2.414 & 6.8 & 293 & 2.24 \\
SH-8 & 0.0066 & 10.6 & -0.008 & 2.7 & 93.33 & 0.275 & 2.969 & 7.2 & 276.5 & 2.25 \\
SH-9 & 0.008 & 11.282 & -0.009 & 3.05 & 111.11 & 0.374 & 2.968 & 8.02 & 312 & 2.13 \\
SH-10 & 0.007 & 12.008 & -0.007 & 3.04 & 71.11 & 0.145 & 3.334 & 9.58 & 301 & 2.35 \\
SH-11 & 0.0004 & 7.455 & -0.024 & 2.92 & 62.22 & 0.241 & 2.694 & 6.34 & 292 & 2.15 \\
SH-12 & 0.0021 & 8.2 & -0.016 & 2.96 & 102.22 & 0.566 & 2.959 & 6.03 & 295.5 & 2.24 \\
\hline
\end{tabular}

${ }^{*} P 1$ is the permeability in $\mathrm{md} ; P 2$ is the porosity in $\% ; P 3$ is the structural curvature in $\mathrm{m}^{-1} ; P 4$ is the average vitrinite reflectance in $\% ; P 5$ is the distance to the nearest fault in $\mathrm{m} ; P 6$ is the specific surface area in $\mathrm{m}^{2} / \mathrm{g} ; P 7$ is the most probable aperture in $\mathrm{nm} ; P 8$ is the Barrett-Joyner-Halenda (BJH) adsorption average pore size in $\mathrm{nm} ; P 9$ is the depth in $\mathrm{m} ; P 10$ is the fractal dimension solution as an analogy. For this, we used the following equation:

$F=(L e / L)^{2} / \phi$.

The ratio $F$ is called the formation factor, and the value of $F$ is the same as that in the Archie formula:

$F=b / \phi^{m}$

where $b$ is an empirical factor $(0.6<b<2)$, and $\mathrm{m}$ is the cementation index or tortuous factor $(1<m<4)$.

Equations (8) and (9) were combined to obtain (10) (Bayles et al. 1989):

$k=\frac{c}{8 a_{v}^{2}} \frac{\phi^{2+m}}{(1-\phi)^{2}}$

where all the components represent the same factors as those given above.

Equation (10) expresses the relationship between permeability and porosity. This equation contains only two parameters ( $c$ and $m$ ). If the semi-empirical constant $c$ and cementation index $m$ are determined, the model can be used to predict permeability. Parameters $c$ and $\mathrm{m}$ can be determined by minimizing the standard deviation $\sigma$ of the regression, which is expressed as follows:

$\sigma^{2}=\frac{1}{N-P} \sum_{j=1}^{N} W_{j}\left[Y_{j}(\exp )-Y_{j}(\text { calc })\right]^{2}$

where, $W_{j}$ is the weighting factor; $P$ is the number of parameters; $N$ is the number of data points, and $Y_{j}(\exp )$ and $Y_{j}($ calc $)$ represent measured and calculated values, respectively.

The improved KC equation model was used to fit the porosity and permeability of 12 coal samples (Fig. 3). Case
1 represents the fitting situation of all samples, while Case 2 is the fitting situation after the removal of SH2 and SH6 samples. The correlation coefficients between permeability and porosity were 0.18 and 0.68 in Case 1 and Case 2 , respectively. The permeability of coal increased with increasing porosity. The low correlation coefficient indicated that permeability was affected by many factors and not by porosity alone.

\subsection{Relationship between structural curvature and permeability}

Structural curvature that affects coal permeability is caused by the tectonic force field, which can accurately reflect the degree of crack development due to the tensile stress in curved rock layers (Liu et al. 2015; Cao et al. 2020). Figure 4

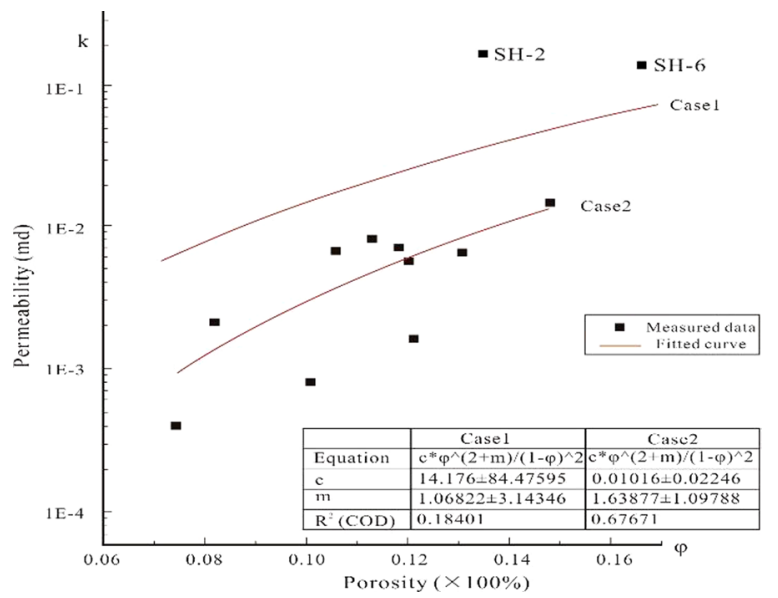

Fig. 3 Fitting curve of coal porosity and permeability based on the extended $\mathrm{KC}$ equation 
shows the curvature descriptions of anticline, syncline, monocline, and flat layers. In the context of the geological structure, the curvature of the anticline is positive, that of the syncline is negative, and those of the plane and monoclinic systems are 0 . In a two-dimensional space, for any surface $S$, the curvature can be uniquely determined by $z=f(x, y)$, and the principal curvature at point $\mathrm{P}$ can be determined using Eq. (12).

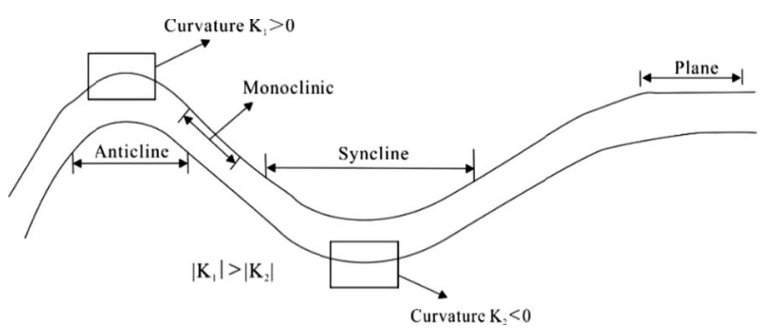

Fig. 4 Geological folds and their curvatures
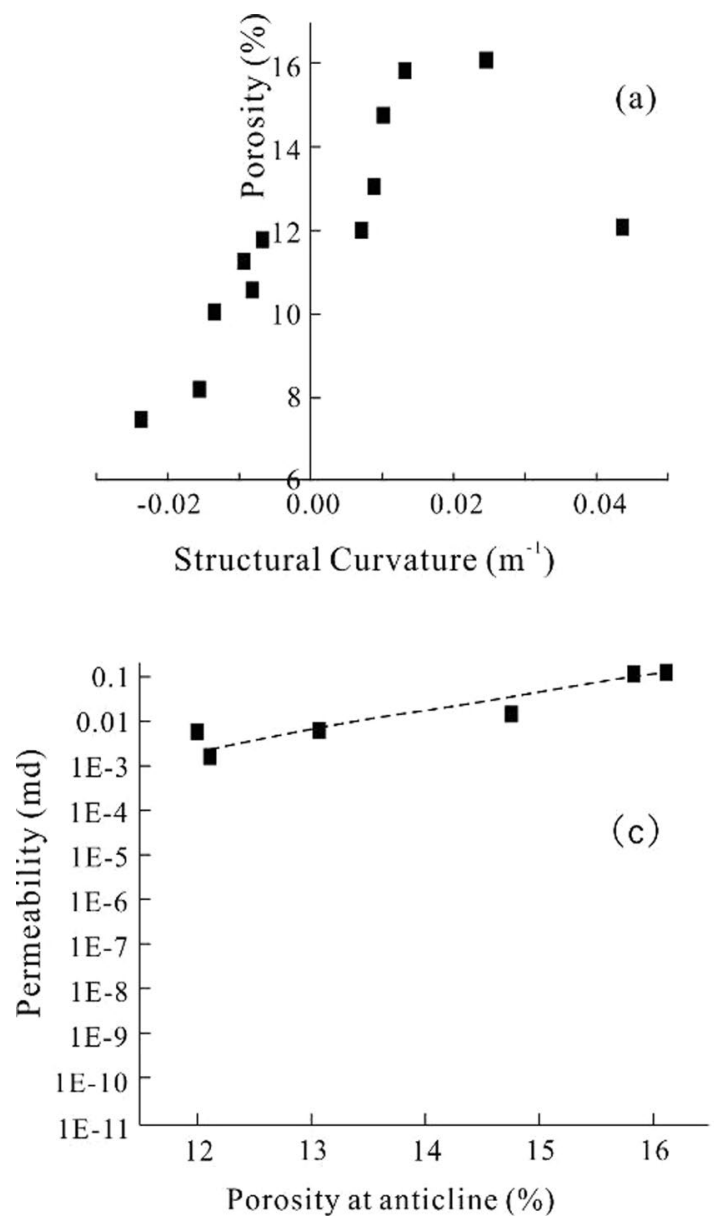

Fig. 5 Interaction of permeability with structural curvature and porosity. a the relationship between structural curvature and porosity, b the relationship between structural curvature and permeability,
$K_{1}, K_{2}=\frac{1}{2}(r+t) \pm \sqrt{\frac{1}{4}(r+t)^{2}+s^{2}}$

where $r=\frac{\partial^{2} f}{\partial x^{2}}$ and $S=\frac{\partial^{2} f}{\partial x \partial y}$. The parameters $r, s$, and $t$ are obtained via the difference method.

The curvature of the sampling point (Table 1) was calculated using the contours of the floor of the coal seam (Fig. 1). The relationship diagrams of structural curvature, permeability, and porosity are displayed in Fig. 5. Figure 5a shows the relationship between structural curvature and porosity. The porosity at the anticline (structural curvature value $>0$ ) was relatively skewed. As structural curvature values of synclines approached zero, porosity values increased. This shows that structural curvature has a significant effect on coal porosity in the No. 3 coal seam, an effect which increased and decreased at anticlines and synclines, respectively.

However, structural curvature did not always increase at anticlines. When structural curvature reached a certain
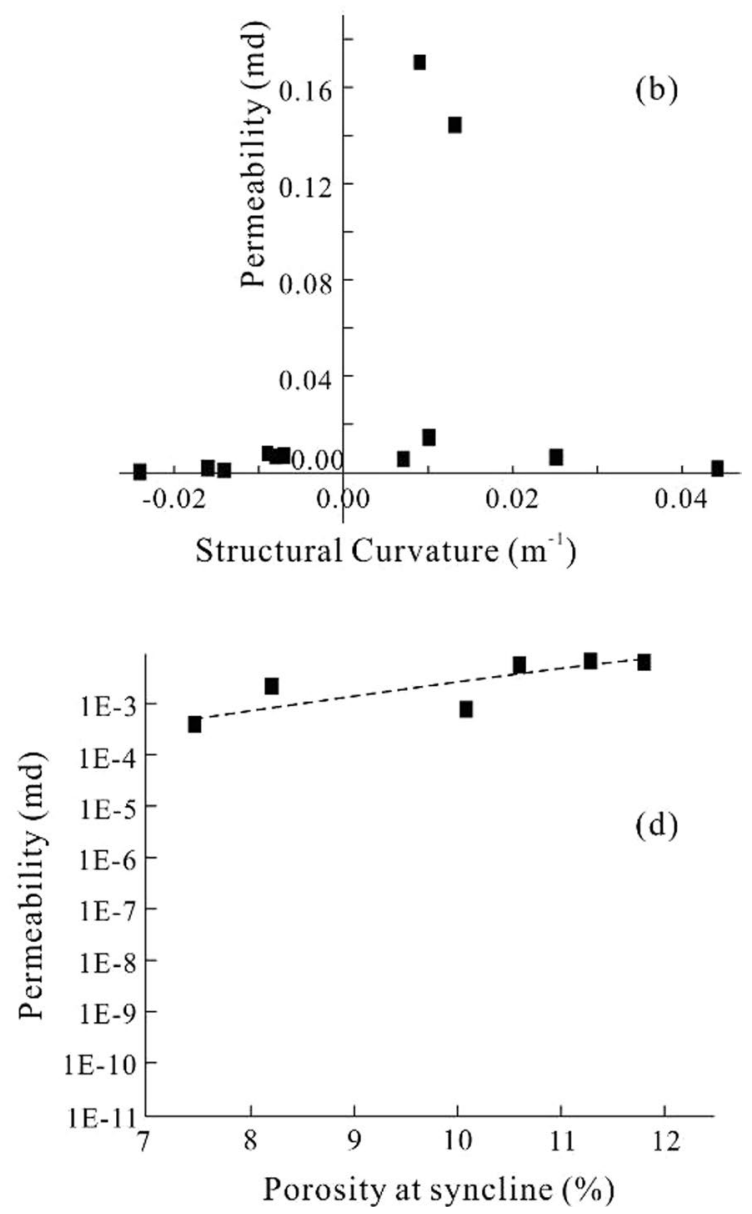

$\mathbf{c}$ the relationship between porosity and permeability at an anticline, $\mathbf{d}$ the relationship between porosity and permeability at a syncline 
level, porosity showed a downward trend probably because as structural curvature increased, pores in coal are filled with minerals. Fig. 5b shows the relationship between structural curvature and permeability. Figure $5 \mathrm{~b}$ shows that permeability of coal at the syncline was low, and the sensitivity to structural curvature was weak. Figure $5 \mathrm{c}$, d show the relationship between porosity and permeability at an anticline and a syncline, respectively; coal porosity and permeability were strong in both. Coal reservoir permeability is related to coal seam fissures and in situ stress, while the geological structure is an underlying factor that controls these two factors.

\subsection{Relationship between vitrinite reflectance and permeability}

With the gradual increase in average vitrinite reflectance, the permeability of the No. 3 coal seam tended to first decrease and then increase. The permeability of coal was the minimum at an average vitrinite reflectance of $2.86 \%$. Figure 6 shows the relationship between average vitrinite reflectance and permeability, after excluding the samples that were collected near faults (SH-2, SH-3, and SH-6). Combined with the analysis of geological data, we observed that average vitrinite reflectance of coal was below $2.86 \%$, coal had a shallow burial depth, and pressure in the reservoir was relatively small. With the increase in burial depth, a higher degree of coal metamorphism was manifested by a higher vitrinite reflectance; the pressure of the formation increased, the level of coalification increased, coal macromolecular functional groups contracted, carbon content increased, and moisture and permeability decreased. However, when the average vitrinite reflectance was greater than $2.86 \%$, the evolution

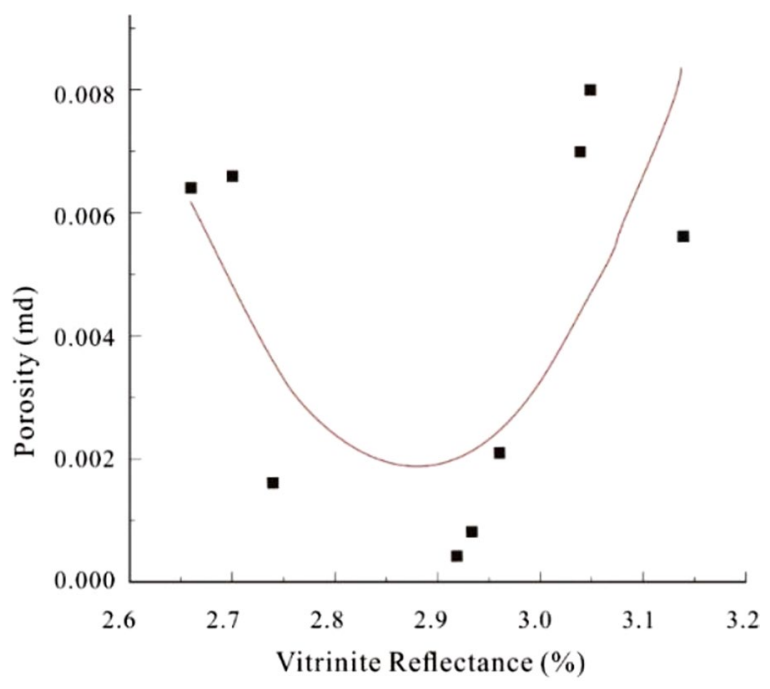

Fig. 6 Relationship between average vitrinite reflectance and permeability continued and the coal generated lighter hydrocarbons ( $\mathrm{Yu}$ et al. 2020); further, the number of micropores and small pores gradually increased, causing an increase in the permeability of coal.

\subsection{Relationship between pore structure characteristics and permeability}

Many classification schemes for pore structures are available as they vary widely in different types of coals. This study employed the International Union of Pure and Applied Chemistry (IUPAC) classification system, in which pores are divided into large pores $(>50 \mathrm{~nm})$, mesopores $(2-50 \mathrm{~nm})$, and micropores $(<2 \mathrm{~nm})$. A static liquid nitrogen adsorption instrument (JW-BK122F) was used to test the pore structures of coal samples using low-temperature liquid nitrogen.

The low-temperature $\mathrm{N}_{2}$ adsorption/desorption isotherms of the coal samples are shown in Fig. 7. The adsorption loops of the coal samples were of type A, which displays a distinct hysteresis loop that develops as capillary condensation occurs in the mesopores indicating that the coal samples had many mesopores. The pores were cylindrical, and the pore shape was open. The loop characteristics of SH-2 and SH-6 were similar, but not precisely like the B-type of the IUPAC classification.

SH-2 and SH-6 presented characteristics of an AB-type hysteresis loop, which was a comprehensive reflection of the true shape of pores of the samples. This indicated that SH-2 and SH-6 coal samples had fractured and cylindrical pores.

The pore shape of the coal samples was irregular, and the pore sizes were also different. The pore shape was characterized by pore volume distribution parameters in different pore size ranges from which the pore size distribution can be calculated based on isothermal adsorption data. Figure 8 displays the distribution of pore volumes and sizes of the 12 samples using the Barrett-Joyner-Halenda (BJH) pore size method. Pore sizes of the samples were approximately 2-8 $\mathrm{nm}$, indicating the development of many mesopores and micropores in the coal samples. Macropores were less developed.

Figure 9 displays the histogram of pore volume distribution based on the IUPAC classification. The pore volumes of 12 coal samples were dominated by mesopores (pore diameter was 2-50 nm), except for in SH-2 coal sample. As the $\mathrm{SH}-2$ coal sample was dominated by fracture-shaped pores generated by stress fracturing, the proportion of large pores exceeded that of micropores. The pore size distributions of the remaining 11 coal samples were studied based on the volume of micropores (pore diameter $<2 \mathrm{~nm}$ ) and the largest pores (pore diameter $>50 \mathrm{~nm}$ ). Meso-, large and micro- pore volumes accounted for $71.38 \%, 18.17 \%$, and $10.45 \%$, respectively. 

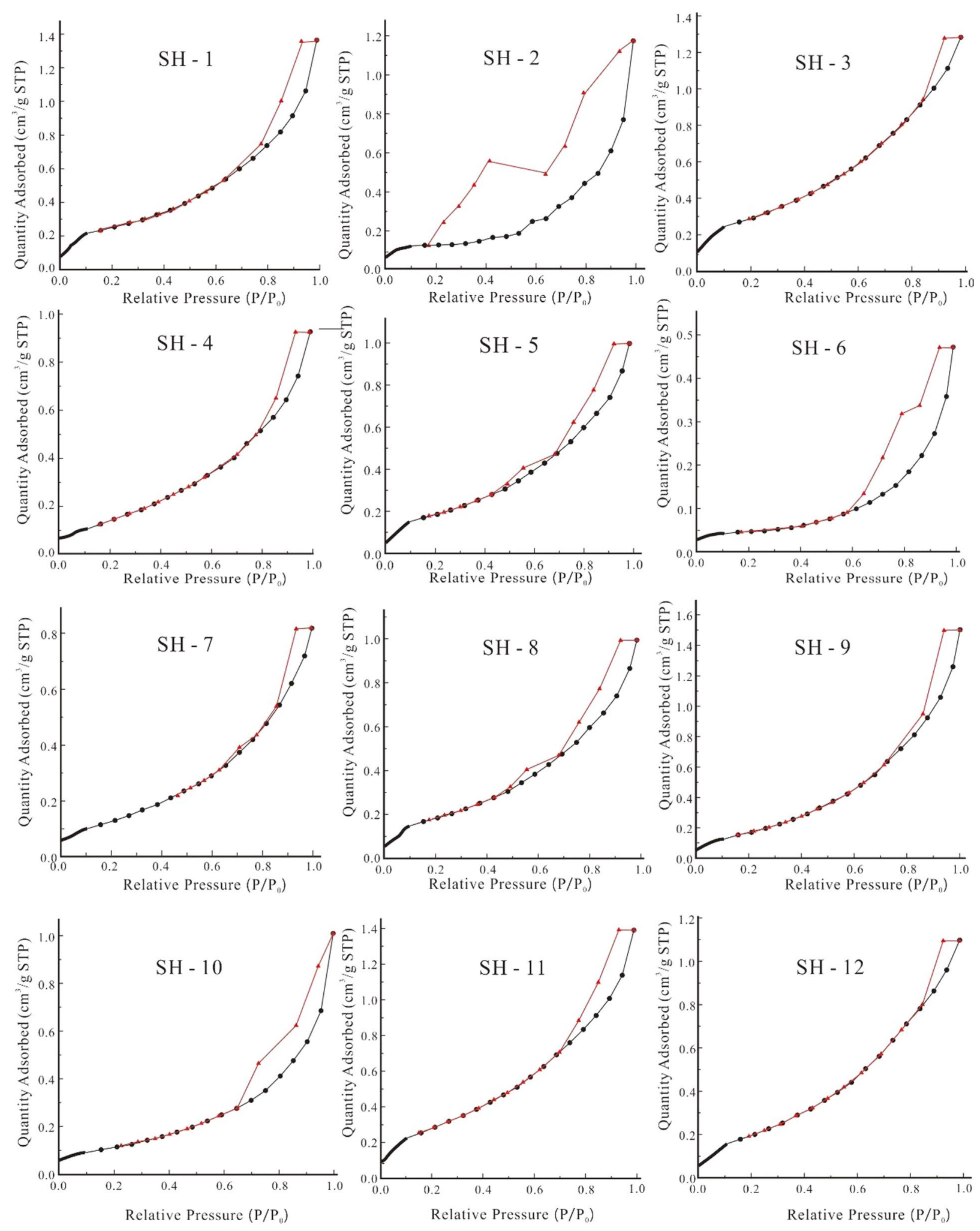

- Adsorption

$\rightarrow$ Desorption

Fig. 7 Low-temperature $\mathrm{N}_{2}$ adsorption/desorption isotherms of the coal samples 

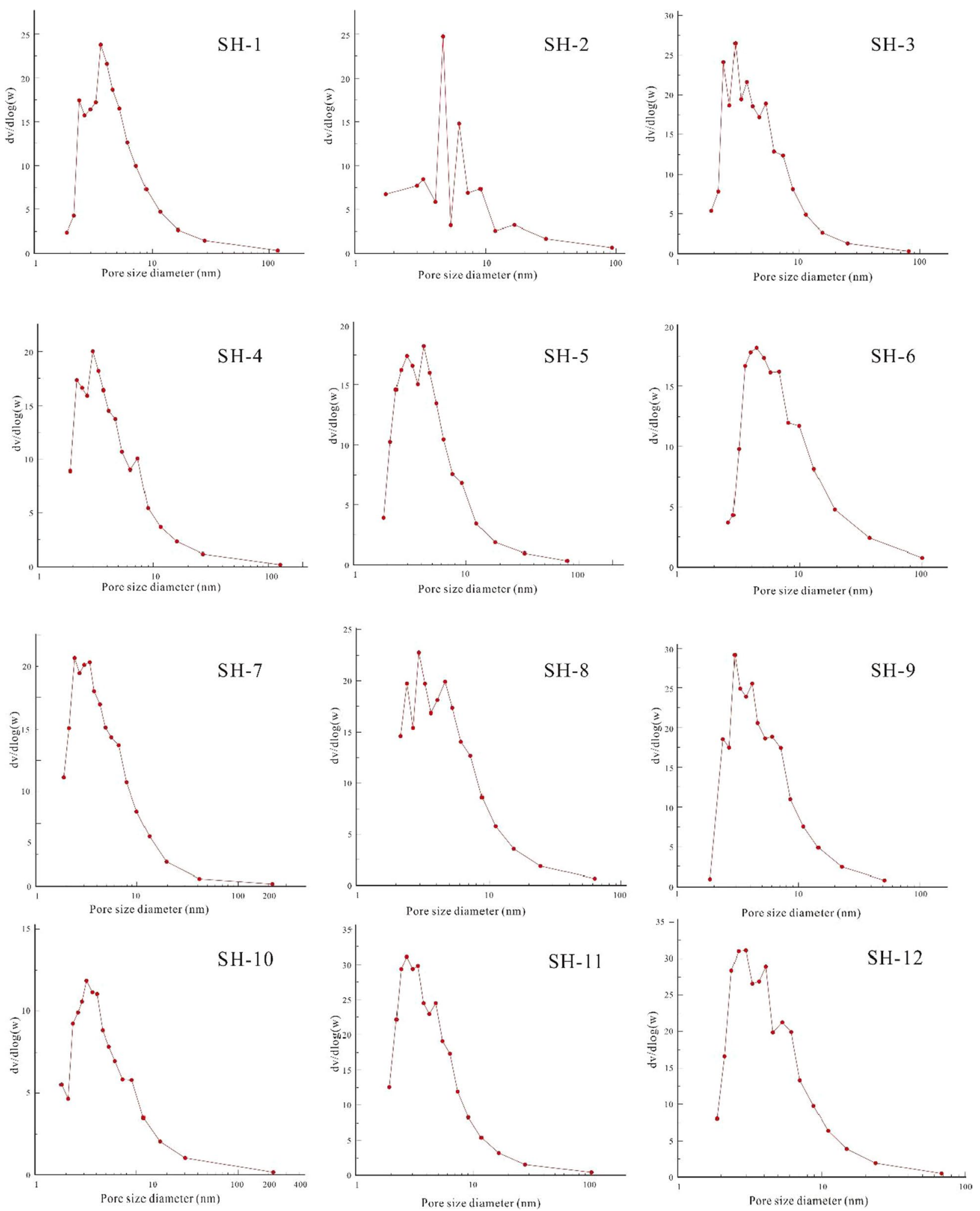

Fig. 8 Pore volume-pore size differential distribution in coal samples 


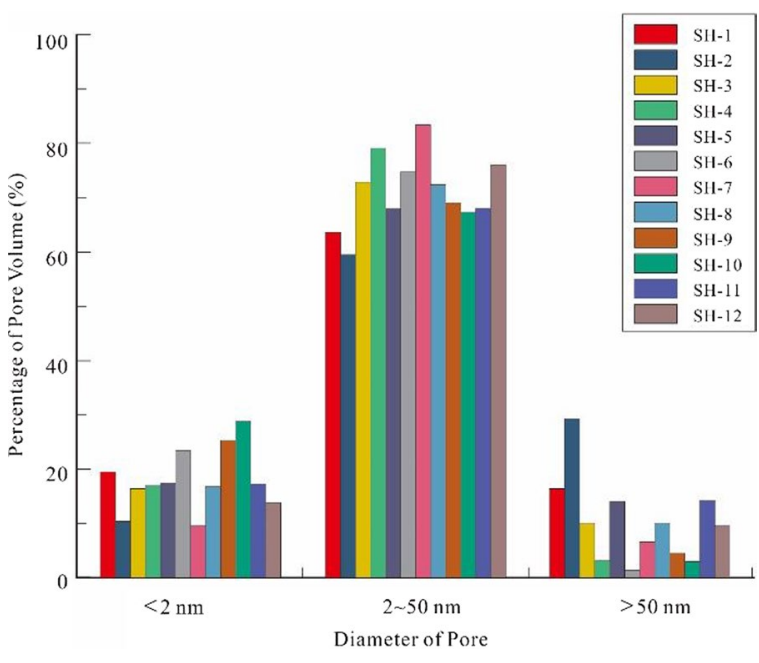

Fig. 9 Histogram of pore volume distribution based on the IUPAC classification

Fractal geometric features can characterize the pore structure and surface irregularities of porous materials. According to the FHH model, the fractal dimensions of the coal samples were obtained from low-temperature $\mathrm{N}_{2}$ adsorption data. Table 1 shows that the FHH fractal dimensions were between 2 and 3 in all coal samples. The fractal dimensions of SH-2 and SH-6 are 2.51 and 2.49, respectively, which are larger than those of the other coal samples. Their corresponding $\mathrm{BJH}$ adsorption, average pore size, and porosity values were also higher, indicating higher permeability compared to other coals. A larger average pore diameter of coal implies higher fractal dimension (more complex pores of coal), higher porosity, better connectivity of pores, and thus higher permeability. The other 10 samples had lower fractal dimensions, smaller pore sizes, and less developed pores, resulting in poor connectivity and low coal permeability.

Linear correlation analyses between permeability and pore structure parameters were carried out and are shown in Fig. 10. Average pore size had the highest correlation coefficient with permeability followed by the most probable pore size, fractal dimension, and specific surface area. This analysis shows that, in the study area, within the average pore size range of 5-13 $\mathrm{nm}$, as the pore size increases, permeability increases.

\subsection{Principal component analysis of permeability control modes}

Although factors that affect permeability of coal are complex, it is important to understand its controlling factors for practical applications. The analysis thus far has indicated that each factor is related to permeability but no individual factor controls it. For example, a close relationship exists between porosity and permeability. However, the correlation coefficient between permeability and porosity is low indicating that permeability is also affected by other factors. Similar findings on the influence of other geological factors on permeability were obtained. Various degrees of correlation exist between these factors; thus, analyses considering these variables individually may introduce redundancy.

The PCA method can transform a group of potentially correlated variables into a group of linearly uncorrelated variables through orthogonal transformation, thus allowing us to identify the primary mode controlling permeability. In PCA, groups of linearly independent attributes comprise the components, and the contribution of an attribute to each principal component is different. Therefore, this study considered coal porosity, structural curvature, vitrinite reflectance, specific surface area, and fractal dimensions to identify principal component modes that control coal permeability.

The properties of the coal samples measured in the experiment are summarized in Table 1. IBM SPSS software was used for the PCA. The coal parameter data were standardized, and then, principal components were determined. We obtained the eigenvalues of the correlation coefficient matrix and their corresponding contributions to variance (Table 2). The variance contribution of the first principal component was $52.585 \%$ (the highest among the components), and the
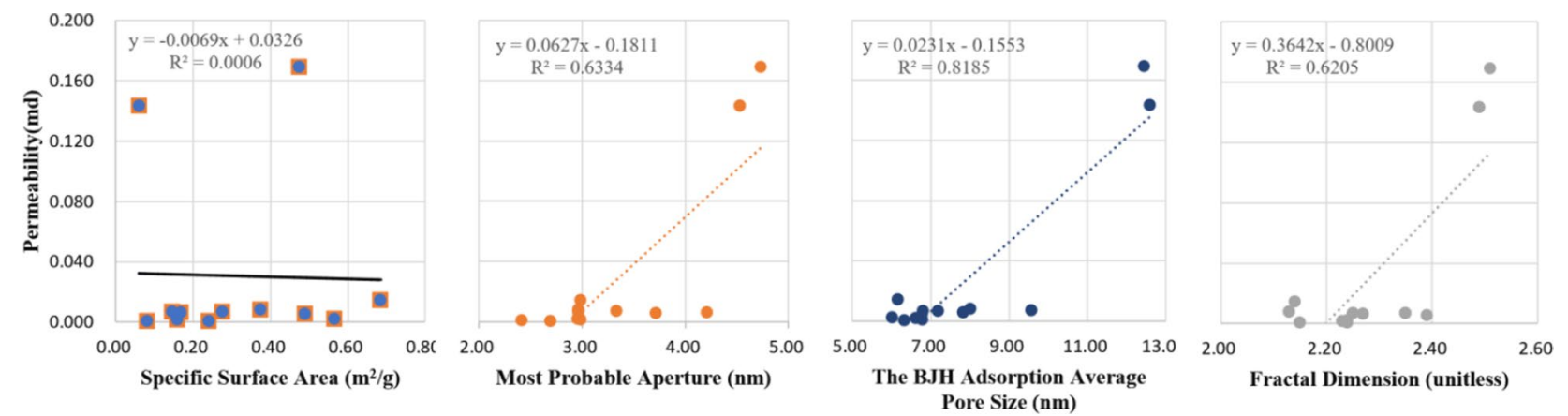

Fig. 10 Linear regression relationship between pore structure and permeability 
Table 2 Eigenvalues of the correlation coefficient matrix and their corresponding contributions to variance

\begin{tabular}{|c|c|c|c|c|c|c|}
\hline \multirow{2}{*}{$\begin{array}{l}\text { Principal } \\
\text { compo- } \\
\text { nent }\end{array}$} & \multicolumn{3}{|c|}{ Initial Eigenvalue } & \multicolumn{3}{|c|}{ Sum of squared loads } \\
\hline & Variance & $\begin{array}{l}\text { Percentage of } \\
\text { variance }(\%)\end{array}$ & $\begin{array}{l}\text { Cumulative per- } \\
\text { centage of variance } \\
(\%)\end{array}$ & Variance & $\begin{array}{l}\text { Percentage of } \\
\text { variance }(\%)\end{array}$ & $\begin{array}{l}\text { Cumulative percent- } \\
\text { age of variance }(\%)\end{array}$ \\
\hline 1 & 4.733 & 52.585 & 52.585 & 4.733 & 52.585 & 52.585 \\
\hline 2 & 1.789 & 19.875 & 72.460 & 1.789 & 19.875 & 72.460 \\
\hline 3 & 1.102 & 12.240 & 84.700 & 1.102 & 12.240 & 84.700 \\
\hline 4 & 0.510 & 5.669 & 90.369 & & & \\
\hline 5 & 0.431 & 4.787 & 95.156 & & & \\
\hline 6 & 0.261 & 2.898 & 98.054 & & & \\
\hline 7 & 0.098 & 1.088 & 99.142 & & & \\
\hline 8 & 0.070 & 0.780 & 99.923 & & & \\
\hline 9 & 0.007 & 0.077 & 100.000 & & & \\
\hline
\end{tabular}

Table 3 Scores of the first, second, and third principal components for different variables

\begin{tabular}{lrrr}
\hline Variable & \multicolumn{3}{c}{ Principal component } \\
\cline { 2 - 4 } & \multicolumn{1}{c}{ First } & Second & Third \\
\hline Porosity (\%) & 0.461 & 0.541 & 0.550 \\
Structural curvature $\left(\mathrm{m}^{-1}\right)$ & -0.554 & 0.618 & -0.081 \\
Average vitrinite reflectance $(\%)$ & 0.828 & -0.263 & -0.404 \\
Distance to nearest fault $(\mathrm{m})$ & -0.763 & 0.387 & -0.272 \\
Specific surface area $\left(\mathrm{m}^{2} / \mathrm{g}\right)$ & 0.047 & -0.717 & 0.563 \\
Most probable aperture $(\mathrm{nm})$ & 0.805 & 0.414 & 0.327 \\
BJH adsorption-based average pore & 0.915 & 0.243 & -0.135 \\
$\quad$ size & & & \\
Depth (m) & 0.859 & -0.219 & -0.331 \\
Fractal dimensions & 0.848 & 0.321 & -0.063 \\
\hline
\end{tabular}

cumulative contribution of the variance of the first three principal components was $84.7 \%$. Therefore, the first three principal components largely explain the variance in the data, and thus, three main modes of permeability control are present in the study area.

Table 3 presents the calculated coefficient score matrix of the components. The absolute value of coefficient score has a directly proportional relationship with the degree of influence of a variable on a principal component. BJH adsorption-based average pore size, depth, and fractal dimensions are the top three variables within the first principal component. These variables involve pore diameter and complexity of coal pore structure, indicating that they have the highest influence on coal permeability.

Correlation analysis of permeability and PCA results showed that correlation coefficients were 0.711 between permeability and the first principal component, 0.072 between permeability and the second principal component, and 0.01 between permeability and the third principal component. The correlation coefficient between permeability and the first and second principal components is 0.751 ; the correlation coefficient between permeability and the first and third principal components is 0.714 ; the correlation coefficient between permeability and the second and third principal components is 0.074 , and the correlation coefficient between permeability and the first, second and third principal components is 0.754 . The results indicate that permeability is controlled by the first principal component. According to the previous analysis, the major geological factors in the first principal component are pore size, depth, and fractal dimension. Based on the $\mathrm{KC}$ equation, the correlation coefficient between porosity and permeability is 0.18 , which is relatively low. However, after removing the two sample points near the fault structure, the correlation coefficient increases to 0.68 . In addition to the correlation coefficient between permeability and the first principal component, the results show that the depth of burial influences pore connectivity and structure influences the complexity of pore shapes (characterized by fractal dimension). Therefore, pore size, burial depth, and fractal dimension are major factors controlling permeability.

The study area features high-rank coal. The coal sampled from the mines was black with a striped structure, black streaks, stepped fractures, and a glassy luster. In terms of abundance, bright coal was followed by dark coal, bright light coal, and simple coal seam structures. The coal was semi-hard, and the dominant gangue was mudstone. Thus, the influencing factors of coal permeability determined via PCA were consistent with the study area's simple geological structure and relatively underdeveloped coal fractures.

In summary, the factors affecting coal permeability are multiple and diverse. The first, second, and third principal components represented different control modes of permeability. The influence of geological factors on permeability varied based on geological conditions. Overall, the main factors affecting permeability of coal were properties of 
the coal itself, such as the average pore size based on $\mathrm{BJH}$ adsorption, depth, and fractal dimensions.

\section{Conclusions}

This study examined the physical properties of 12 coal samples obtained from the No. 3 coal seam in the Sihe coal mine. Coal characteristics such as porosity, permeability, isothermal adsorption-based pore size, and vitrinite reflectivity were evaluated. Structural curvature was calculated based on the contour of the floor of the coal seam, and the pore fractal dimensions were calculated using the $\mathrm{FHH}$ model.

Geological factors influencing coal permeability characteristics were determined, and the main controlling factors were analyzed using PCA. The main conclusions are as follows:

(1) Coal permeability and porosity were analyzed based on the porosity-permeability model derived from the Archie formula and the $\mathrm{KC}$ equation. Coal permeability increased with an increase in porosity (porosity increased from $8 \%$ to $16 \%$, and permeability increased from 0.0012 to $0.018 \mathrm{md}$ ).

(2) The effect of structural curvature on permeability was most evident when the curvature of the anticline structure was $0.015-0.030 \mathrm{~m}^{-1}$. Curvatures lower than $0.015 \mathrm{~m}^{-1}$ or higher than $0.03 \mathrm{~m}^{-1}$ were not conducive to high levels of permeability. As structural curvature increased from -0.0239 to $-0.0068 \mathrm{~m}^{-1}$, permeability increased from 0.0008 to $0.008 \mathrm{md}$.

(3) With a gradual increase in the average vitrinite reflectance, permeability tended to first decrease and later increase. The minimum permeability value was reached at an average vitrinite reflectance of $2.86 \%$.

(4) At the microscopic level, the degree of pore development can be characterized based on porosity and pore fractal dimensions. The greater the porosity, the more complex the pore structure. The higher the degree of micropore development, the better the connectivity of pores (permeability). On the other hand, the lower the porosity, the lower the degree of pore development. The more uniform the pore size, the lower the permeability.

(5) The control mode of coal permeability in the Sihe coal mine was analyzed using PCA. The data were divided into three principal components. Since each principal component is a combination of multiple geological factors, the principal components are orthogonal to each other, each representing a permeability control mode. The first principal component represented the influence of pore size, burial depth, and pore complexity on permeability. The second principal component repre- sented the influence of specific surface area, structural curvature, and porosity. The third principal component included specific surface area, porosity, and average vitrinite reflectance. In general, pore diameter and pore complexity of coal had a major impact on its permeability.

The results of the present study, which explored factors influencing coal permeability, suggest that researchers and stakeholders in the coal industry need to consider not only distinct properties but also interactions among multiple properties of coal. The results of the present study could facilitate the efficient utilization of coalbed methane resources.

Acknowledgements We would like to thank the anonymous reviewers for providing us critical comments to improve the quality of this manuscript. We are also grateful to the geological engineers of the Sihe coal mine for their support throughout the geological data acquisition process.

Authors' contributions GZ: data experiment and article writing; QZ: data analysis based on principal component analysis; SP: framework and guidance for this article; JS: porosity, permeability, and pore size data analysis; DT: SEM data analysis; CJ: seismic data analysis; YC: vitrinite reflectance analysis. All authors read and approved the final manuscript.

Funding This research was supported in part by the National Key R\&D Program of China (2018YFC0807803) and the Science and Technology Major Project from Shanxi Province (MQ2015-02).

Availability of data and materials Not applicable.

Code availability Not applicable.

\section{Declarations}

Competing interests The authors declare that they have no competing interests.

Open Access This article is licensed under a Creative Commons Attribution 4.0 International License, which permits use, sharing, adaptation, distribution and reproduction in any medium or format, as long as you give appropriate credit to the original author(s) and the source, provide a link to the Creative Commons licence, and indicate if changes were made. The images or other third party material in this article are included in the article's Creative Commons licence, unless indicated otherwise in a credit line to the material. If material is not included in the article's Creative Commons licence and your intended use is not permitted by statutory regulation or exceeds the permitted use, you will need to obtain permission directly from the copyright holder. To view a copy of this licence, visit http://creativecommons.org/licenses/by/4.0/. 


\section{References}

Bayles GA, Klinzing GE, Chiang S-H (1989) Fractal mathematics applied to flow in porous systems. Part Syst Char 6:168-175. https://doi.org/10.1002/ppsc.19890060128

Cao L, Yao Y, Liu D, Yang Y, Wang Y, Cai Y (2020) Application of seismic curvature attributes in the delineation of coal texture and deformation in Zhengzhuang field, southern Qinshui Basin. Am Assoc Pet Geol Bull 104:1143-1166. https://doi.org/10.1306/ 12031918208

Du Y, Du D (2018) Fault detection and diagnosis using empirical mode decomposition based principal component analysis. Comput Chem Eng 115:1-21. https://doi.org/10.1016/j.compchemeng. 2018.03.022

Fan L, Liu S (2018) Numerical prediction of in situ horizontal stress evolution in coalbed methane reservoirs by considering both poroelastic and sorption induced strain effects. Int J Rock Mech Min 104:156-164. https://doi.org/10.1016/j.ijrmms.2018.02.012

Fan L, Liu S (2019) Evaluation of permeability damage for stressed coal with cyclic loading: an experimental study. Int J Coal Geol 216:103338. https://doi.org/10.1016/j.coal.2019.103338

Gamson PD, Beamish BB, Johnson DP (1993) Coal microstructure and micropermeability and their effects on natural gas recovery. Fuel 72:87-99. https://doi.org/10.1016/0016-2361(93)90381-B

Ha D, Ahmed U, Pyun H, Lee CJ, Baek KH, Han C (2017) Multi-mode operation of principal component analysis with k-nearest neighbor algorithm to monitor compressors for liquefied natural gas mixed refrigerant processes. Comput Chem Eng 106:96-105. https://doi. org/10.1016/j.compchemeng.2017.05.029

Harpalani S, Schraufnagel RAJF (1990) Shrinkage of coal matrix with release of gas and its impact on permeability of coal. Fuel 69:551556. https://doi.org/10.1016/0016-2361(90)90137-F

Lam BSY, Chu AMY, Yan H (2020) Statistical bootstrap-based principal mode component analysis for dynamic background subtraction. Pattern Recognit 100:107153. https://doi.org/10.1016/j. patcog.2019.107153

Liu G, Zhu YM, Hou XW, Cui ZB (2015) Kaiping coalfield structure curvature and coalbed methane occurrence characteristics. Coal Technol 11:123-125

Makinde I, Lee WJ (2019) Principal components methodology: a novel approach to forecasting production from liquid-rich shale (LRS) reservoirs. Petroleum 5:227-242. https://doi.org/10.1016/j.petlm. 2018.08.002

Mao Q, Fang X, Hu Y, Li G (2018) Chiller sensor fault detection based on empirical mode decomposition threshold denoising and principal component analysis. Appl Therm Eng 144:21-30. https://doi.org/10.1016/j.applthermaleng.2018.07.104

Qin Y, Zhang D, Fu X, Lin D, Ye J, Xu Z (1999) A discussion on correlation of modern tectonic stress field to physical properties of coal reservoirs in central and southern Qinshui Basin. Geol Rev 45:576-583

Shen J, Qin Y, Fu X, Wang B, Yang S, Zhao L (2010) Application of structural curvature of coalbed floor on CBM development in the Zaoyuan block of the southern Qinshui Basin. Min Sci Technol 20:886-890. https://doi.org/10.1016/S1674-5264(09)60301-X

Shi R, Liu J, Wei M, Elsworth D, Wang X (2018a) Mechanistic analysis of coal permeability evolution data under stress-controlled conditions. Int J Rock Mech Min Sci 110:36-47. https://doi.org/10. 1016/j.ijrmms.2018.07.003

Shi X, Pan J, Hou Q, Jin Y, Wang Z, Niu Q, Li M (2018b) Micrometerscale fractures in coal related to coal rank based on micro-CT scanning and fractal theory. Fuel 212:162-172. https://doi.org/ 10.1016/j.fuel.2017.09.115

Tran NM, Burdejová P, Ospienko M, Härdle WK (2019) Principal component analysis in an asymmetric norm. J Multivar Anal 171:1-21. https://doi.org/10.1016/j.jmva.2018.10.004

Wang LL, Vandamme M, Pereira JM, Dangla P, Espinoza N (2018) Permeability changes in coal seams: the role of anisotropy. Int $\mathbf{J}$ Coal Geol 199:52-64. https://doi.org/10.1016/j.coal.2018.09.014

Yao Y-B, Liu D-M (2009) Microscopic characteristics of microfractures in coals: an investigation into permeability of coal. Procedia Earth Planet Sci 1:903-910. https://doi.org/10.1016/j.proeps. 2009.09.140

Yao H, Kang Z, Li W (2014) Deformation and reservoir properties of tectonically deformed coals. Petrol Explor Dev 41:460-467. https://doi.org/10.1016/S1876-3804(14)60052-5

Yu K, Ju Y, Zhang B (2020) Modeling of tectono-thermal evolution of Permo-Carboniferous source rocks in the southern Qinshui Basin, China: consequences for hydrocarbon generation. J Pet Sci Eng 193:107343. https://doi.org/10.1016/j.petrol.2020.107343

Zhang G, Ranjith PG, Liang W, Haque A, Perera MSA, Li D (2019) Stress-dependent fracture porosity and permeability of fractured coal: An in-situ X-ray tomography study. Int J Coal Geol 213:103279. https://doi.org/10.1016/j.coal.2019.103279

Publisher's Note Springer Nature remains neutral with regard to jurisdictional claims in published maps and institutional affiliations. 